\title{
Magnolol Induces Apoptosis and Inhibits ERK-modulated Metastatic Potential in Hepatocellular Carcinoma Cells
}

\author{
LIN-YEN KUAN $^{1,2^{*}}$, WEI-LUNG CHEN ${ }^{1,2 *}$, JIANN-HWA CHEN $^{1,2}$, FEI-TING HSU $^{3}$, TSU-TE LIU ${ }^{4}$, WEI-TING \\ $\mathrm{CHEN}^{5}$, KAI-LEE WANG ${ }^{6}$, WEN-CHANG CHEN ${ }^{7,8}$, YU-CHANG LIU ${ }^{8,9,10^{*}}$ and WEI-SHU WANG ${ }^{11,12^{*}}$ \\ ${ }^{1}$ Department of Emergency Medicine, Cathay General Hospital, Taipei, Taiwan, R.O.C.; \\ ${ }^{2}$ School of Medicine, Fu Jen Catholic University, Taipei, Taiwan, R.O.C.; \\ ${ }^{3}$ Department of Biological Science and Technology, China Medical University, Taichung, Taiwan, R.O.C.; \\ ${ }^{4}$ Division of Gastroenterology, Department of Internal Medicine, \\ National Yang-Ming University Hospital, Yilan, Taiwan, R.O.C.; \\ ${ }^{5}$ Department of Psychiatry, Zuoying Branch of Kaohsiung Armed Forces General Hospital, Kaohsiung, Taiwan, R.O.C.; \\ ${ }^{6}$ Department of Nursing, Ching Kuo Institute of Management and Health, Keelung, Taiwan, R.O.C.; \\ ${ }^{7}$ Department of Diagnostic Radiology, Chang Gung Memorial Hospital, Chiayi Branch, \\ Chang Gung University of Science and Technology, Chiayi, Taiwan, R.O.C.; \\ ${ }^{8}$ Department of Medical Imaging and Radiological Science, \\ Central Taiwan University of Science and Technology, Taichung, Taiwan, R.O.C.; \\ ${ }^{9}$ Department of Radiation Oncology, National Yang-Ming University Hospital, Yilan, Taiwan, R.O.C.; \\ ${ }^{10}$ Department of Radiation Oncology, Chang Bing Show-Chwan Memorial Hospital, Changhua, Taiwan, R.O.C.; \\ ${ }^{11}$ Department of Medicine, National Yang-Ming University Hospital, Yilan, Taiwan, R.O.C.; \\ ${ }^{12}$ School of Medicine, National Yang-Ming University, Taipei, Taiwan, R.O.C.
}

\begin{abstract}
Background/Aim: The aim of the present study was to evaluate the anti-cancer effect of magnolol in hepatocellular carcinoma (HCC) cells in vitro. Materials and Methods: HCC SK-Hepl cells were treated with different concentrations of magnolol or PD98059 [extracellular-signal-regulated kinase (ERK) inhibitor] for $48 \mathrm{~h}$, and then cell viability, apoptosis, signal transduction, expression of anti-apoptotic and metastasis-related proteins, and cell invasion were investigated by [3-(4,5-Dimethylthiazol-2-yl)-2,5-diphenyltetrazolium bromide] (MTT) assay, flow cytometry, nuclear factor kappa $B$
\end{abstract}

This article is freely accessible online.

*These Authors contributed equally to this study.

Correspondence to: Yu-Chang Liu, Department of Radiation Oncology, National Yang-Ming University Hospital, No. 152, Xinmin Rd., Yilan City, Yilan County 26042, Taiwan, R.O.C. Tel: +88639325192 ext.73181, e-mail: kevinyc.liu@gmail.com; WeiShu Wang, Department of Medicine, National Yang-Ming University Hospital, No.169, Siaoshe Rd., Yilan City, Yilan County 26058, Taiwan, R.O.C. Tel: +886 39325192 ext. 12204, e-mail: 11313@ymuh.ym.edu.tw

Key Words: Magnolol, extracellular-signal-regulated kinase, apoptosis, hepatocellular carcinoma.
$(N F-k B)$ reporter gene, western blotting, and cell invasion assays. Results: Magnolol significantly induced accumulation of sub-G $G_{1}$ phase and caspase-3 activation and inhibited $N F-k B$ activation, cell invasion, expression of phosphorylated ERK (pERK), anti-apoptotic and metastatic-related proteins. ERK inactivation was required for magnolol-induced inhibition of metastatic potential of SK-Hepl cells. Conclusion: Taken together, these results indicated that magnolol not only induced apoptosis, but also inhibited ERK-modulated metastatic potential of HCC SK-Hepl cells.

Hepatocellular carcinoma (HCC), a primary malignancy of the liver, is often diagnosed at an advanced stage resulting in poor prognosis (1). Active anti-apoptotic mechanisms and metastasis are contributed to treatment failure in $\operatorname{HCC}(2,3)$. However, HCC has been known to be resistant to conventional chemotherapy and radiotherapy (4). Multi-kinase inhibitors including sorafenib and regorafenib are used for the treatment of advanced HCC. Previous studies presented that both sorafenib and regorafenib not only induced apoptosis, but also inhibited the metastasic potential of HCC cells in vitro and in vivo $(5,6)$. Therefore, development of novel agents that induce apoptosis and inhibit the metastatic potential may offer benefits for patients with HCC.

Herbal medicine has a long history in the treatment of liver disease. Many herbal compounds have been indicated 
to suppress HCC proliferation, survival, and metastasis through induction of apoptosis and inhibition of signaling transduction which participates in tumor progression (7-9). In addition, some studies reported herbal medicine combined with chemotherapy to improve survival and tumor response compared to chemotherapy alone in the treatment of patients with HCC (10). Shenqi mixture (SQM), a herbal composite formula obtained from Ginseng root and Mongolian milkvetch root, combined with microwave coagulation was also used for the treatment of HCC. The combination of SQM and microwave coagulation not only killed the tumor and prevented recurrence, but also promoted life quality and prolonged survival of patients (11).

Magnolol, a multifunctional component derived from Chinese herb Magnolia officinalis, has been shown to possess anti-viral, anti-inflammatory, anti-microbial, cardiovascular and neuroprotective effects $(12,13)$. Magnolol-induced apoptosis in different types of cancer cells, including lung, colon, and prostate cancer cells was also presented (14). Magnolol triggers apoptosis by inducing extrinsic and intrinsic apoptotic pathways in HCC (15). However, the anti-metastatic effect of magnolol in HCC is ambiguous. Therefore, this study investigated whether magnolol induces apoptosis and inhibits metastatic potential in $\mathrm{HCC}$.

\section{Materials and Methods}

Reagents. Magnolol, MTT (3-(4,5-Dimethylthiazol-2-yl)-2,5Diphenyltetrazolium Bromide) and dimethyl sulfoxide (DMSO) were purchased from Sigma-Aldrich (St. Louis, MO, USA). Magnolol was dissolved by DMSO and prepared as stock at $10 \mathrm{mM}$. Matrigel matrix was purchased from Corning Incorporated (Corning, NY, USA). Extracellular signal-regulated kinases (ERK) inhibitor PD98059 was bought from Selleckchem (Houston, TX, USA). jetPEI ${ }^{\mathrm{TM}}$ transfection agent was purchased from Polyplus Transfection (Illkirch, Bas-Rhin, France). D-luciferin was obtained from Promega (Madison, WI, USA).

Cell culture. Human hepatocellular carcinoma SK-Hep1 cells were given by professor Jing-Gung Chung at Department of Biological Science and Technology, China Medical University (Taichung, Taiwan). Cells were maintained in Dulbecco's Modified Eagle Medium (DMEM) with $10 \%$ fetal bovine serum and $1 \%$ penicillinstreptomycin $(100 \mu \mathrm{g} / \mathrm{ml})$ at $37^{\circ} \mathrm{C}$ under a humidified atmosphere of $95 \%$ air and $5 \% \mathrm{CO}_{2} .\left(\right.$ Gibco $^{\mathrm{TM}}$, Thermo Fisher Scientific Inc., Waltham, MA, USA).

Plasmid transfection and stable clone selection. NF-kB luciferase reporter vector ( $\mathrm{pNF}-\mathrm{kB} / \mathrm{luc} 2$ ) was bought from Promega (Madison, WI, USA). $1 \times 10^{6}$ SK-Hep1 cells were seeded into $10 \mathrm{~cm}$ dish and incubated overnight. Cells were transfected with $\mathrm{pNF}-\mathrm{kB} / \mathrm{luc} 2 \mathrm{using}$ jetPEI ${ }^{\mathrm{TM}}$ transfection agent using a commercially available kit under the manufacturer's instructions as described in our previous study (16). After transfection, cells were maintained in culture medium supplemented with $200 \mu \mathrm{g} / \mathrm{ml}$ of hygromycin B for two weeks. After hygromycin B selection, survival clones were maintained in culture medium containing $50 \mu \mathrm{g} / \mathrm{ml}$ of hygromycin $\mathrm{B}$ and the function of NF-kB reporter gene was monitored by using Xenogen IVIS imaging system 200 series (Xenogen, Alameda, CA, USA).

MTT assay. MTT was prepared as $50 \mathrm{mg} / \mathrm{ml}$ stock with phosphatebuffered saline (PBS). $3 \times 10^{4}$ SK-Hep1 cells were seeded in 96-well plates for $24 \mathrm{~h}$, then $70 \%$ confluent cells were treated with various concentrations of magnolol $(0-150 \mu \mathrm{M}$ in $0.1 \%$ DMSO) for another $48 \mathrm{~h}$. Medium of each well was then replaced by fresh medium with MTT reagents (DMEM medium:MTT=9:1) and incubated for $4 \mathrm{~h}$. Before absorbance measurement, medium was replaced by DMSO and placed on a shaker for $10 \mathrm{~min}$ (3). The absorbance of each well was measured at $570 \mathrm{~nm}$ by using a Tecan Sunrise Absorbance Microplate Reader (Tecan Group Ltd., Männedorf, Switzerland).

Cell cycle analysis. $2 \times 10^{5}$ SK-Hep1 cells were cultured overnight in 12-well plates and then treated with 0,50 and $100 \mu \mathrm{M}$ of magnolol for $48 \mathrm{~h}$. After magnolol treatment, cells were harvested by centrifugation, fixed with $75 \%$ ethanol and stored at $-20^{\circ} \mathrm{C}$ overnight. Cells were then stained by propidium iodide (PI) buffer (40 $\mu \mathrm{g} / \mathrm{ml} \mathrm{PI,} 100 \mu \mathrm{g} / \mathrm{ml}$ RNase and $1 \%$ Triton X-100 in PBS) for $30 \mathrm{~min}$ and analyzed by using flow cytometry (FACSCalibur; Becton-Dickinson, Franklin Lakes, NJ, USA) as previously described (16). The sub- $\mathrm{G}_{1}$ phase was defined as the apoptotic population of cells, and the quantification analysis was performed by FlowJo 7.6.1 system.

Caspase-3 activity assay. $2 \times 10^{5}$ SK-Hep1cells were seeded in 12-well plates and maintained overnight. Then, cells were administrated with 0,50 and $100 \mu \mathrm{M}$ magnolol, respectively, for 48 $\mathrm{h}$ and collected for evaluation of caspase- 3 activity. Cells were resuspended and stained with FITC-DEVD-FMK buffer $(1 \mu 1$ (FITC-Asp(OCH3)-Glu(OCH3)-Val-Asp(OCH3)-fluoromethyl ketone (DEVD-FMK) antibody in $300 \mu \mathrm{PBS}$ ) at $37^{\circ} \mathrm{C}$ for $30 \mathrm{~min}$. Cells were then washed with caspase- 3 wash buffer provided from CaspGLOW $^{\mathrm{TM}}$ Fluorescein Active Caspase-3 Staining Kit (BioVision Research Products, Palo Alto, CA, USA). Finally, the activation of caspase-3 was analyzed by flow cytometry as described by Chiang et al. (2).

$N F-\kappa B$ reporter gene assay. SK-Hep1/NF-kB/luc2 cells were seeded into 96 -well plates with $2 \times 10^{4}$ cells/well and maintained overnight. Cells were treated with different concentrations of magnolol $(0-150 \mu \mathrm{M})$ or PD98059 $(0-20 \mu \mathrm{M})$ for $48 \mathrm{~h}$. After drug administration, $100 \mu \mathrm{l}$ of $500 \mu \mathrm{M}$ D-luciferin was added to each well and plates were incubated in the dark for $5 \mathrm{~min}$. The NF-kB activation of SK-Hep1/NF-kB/luc2 cells was finally determined by IVIS imaging system at an acquisition time of $1 \mathrm{~min}$. Subsequently, cell viability in each well was evaluated with MTT assay and used to standardize relative NF-kB activity (5).

Western blot. $3 \times 10^{6}$ SK-Hep1 cells were grown overnight in $10 \mathrm{~cm}$ dishes and then treated with 0,50 and $100 \mu \mathrm{M}$ magnolol or $15 \mu \mathrm{M}$ PD98059 for $48 \mathrm{~h}$, respectively. After treatments, proteins from cells were extracted using lysis buffer $(50 \mathrm{mM}$ Tris- $\mathrm{HCl} \mathrm{pH} 8.0,120 \mathrm{mM}$ $\mathrm{NaCl}, 0.5 \% \mathrm{NP}-40$, and $1 \mathrm{mM}$ phenylmethanesulfonyl fluoride). Equal amount of proteins were separated by electrophoresis in $8-12 \%$ SDS-PAGE gels, transferred to PVDF membranes and blocked by $5 \%$ fat free milk. Membranes were probed with any of anti-survivin (ab76424, Abcam plc., Cambridge, UK), anti-X-linked inhibitor of apoptosis protein (XIAP) (PA5-29253, Thermo Fisher Scientific), 


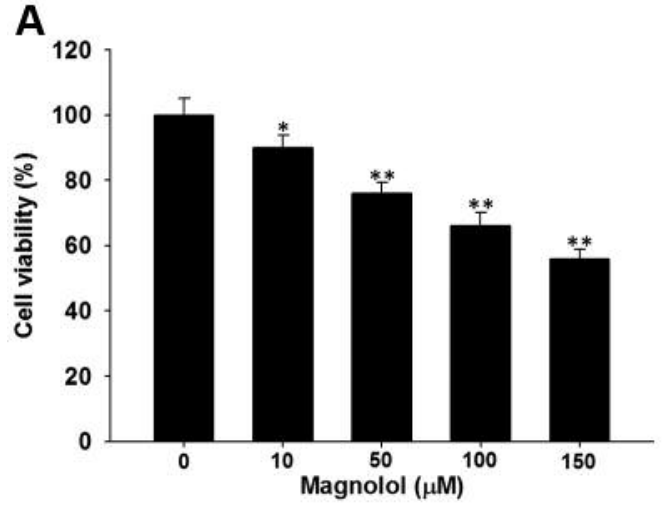

B
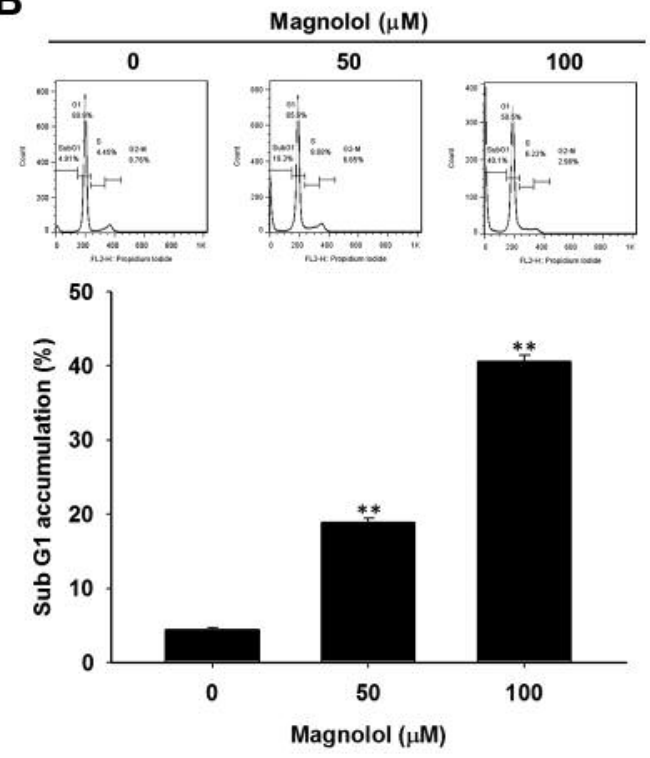

C
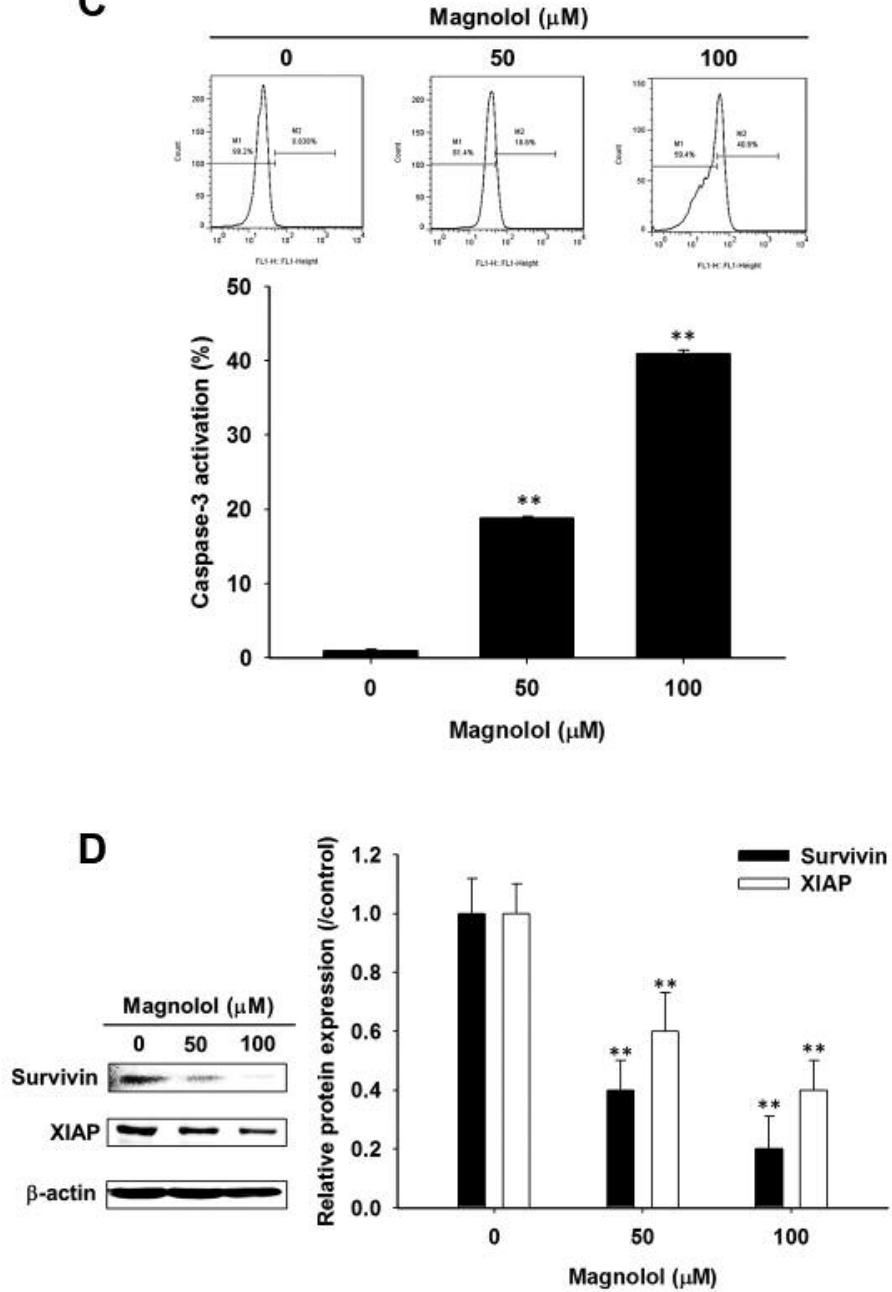

Figure 1. Effect of magnolol on cell viability and apoptosis in SK-Hepl cells. Cells were treated with 0-150 $\mu$ M magnolol for 48 h. A) Evaluation of cell viability was executed by the MTT assay. B) Cell-cycle distribution and C) caspase-3 activity were investigated with flow cytometry. D) Protein levels of survivin and XIAP were evaluated with western blot analysis. ${ }^{*} p<0.05$ and ${ }^{*} p<0.01$ compared to control $(0.1 \%$ DMSO treatment).

anti-MMP2 antibody (ag0549, ProteinTech Group Inc., Chicago, IL, USA), anti-MMP-9 antibody (ab 19016, EMD Millipore Corporation, Burlington, MA, USA), anti-Erk1/2 antibody clone MK12 (sc-154, Santa Cruz Biotechnology, Inc. Dallas, TX, USA), anti-phosphoErk1/2 antibody (Thr202/Tyr204, Thr185/Tyr187, Cell Signaling Technology, Inc., Danvers, MA, USA), anti-uPA antibody (ab169754, Abcam plc.), or anti-beta actin antibody (sc-47778, Santa Cruz Biotechnology, Inc.), washed, and incubated with secondary antibodies coupled to horseradish peroxidase. The PVDF membranes were interacted with Immobilon Western Chemiluminescent HRP Substrate kit (Pierce, Rockford, IL, USA), and protein bands were then visualized and quantified by ChemiDoc MP Imaging System (Bio-Rad Laboratories, Inc., Hercules, CA, USA) (17).

Transwell invasion assay. $8 \mu \mathrm{m}$ pore size transwell insert was coated with $50 \mu \mathrm{l}$ matrigel solution (matrigel diluted 1:1 with DMEM) and placed overnight at a $37^{\circ} \mathrm{C}$ incubator. $3 \times 10^{6} \mathrm{SK}-\mathrm{Hep} 1$ cells were cultured overnight in $10 \mathrm{~cm}$ dishes and treated with 0,50 and $100 \mu \mathrm{M}$ magnolol or $15 \mu \mathrm{M}$ PD98059 for $48 \mathrm{~h}$. After treatments, trypan blue was used to rapidly evaluate cell viability and then $1 \times 10^{6}$ viable cells were collected by centrifugation and resuspended in $1 \mathrm{ml}$ serum-free DMEM. The upper chamber of the transwell insert was filled with $100 \mu \mathrm{l}$ cell suspension and the lower chamber with $200 \mu \mathrm{l}$ DMEM containing $10 \%$ serum and incubated for another $48 \mathrm{~h}$ at $37^{\circ} \mathrm{C}$ in a $\mathrm{CO}_{2}$ incubator. After incubation, cells that invaded the transwell membrane were fixed with a mixture of 3:1 methanol and acetic acid and stained with $3 \%$ crystal violate, air-dried for $15 \mathrm{~min}$ and then photographed with a microscope (Nikon ECLIPSE Ti-U) at $\times 100$ and quantified by ImageJ software (version 1.50, National Institutes of Health, Bethesda, MD, USA) (18).

Statistical analysis. The individual comparison between groups was performed by Student's $t$-test. Generally, graphs represent mean $\pm \mathrm{SE}$ with relevant $p$-values. $p<0.05$ was considered as significant, and 

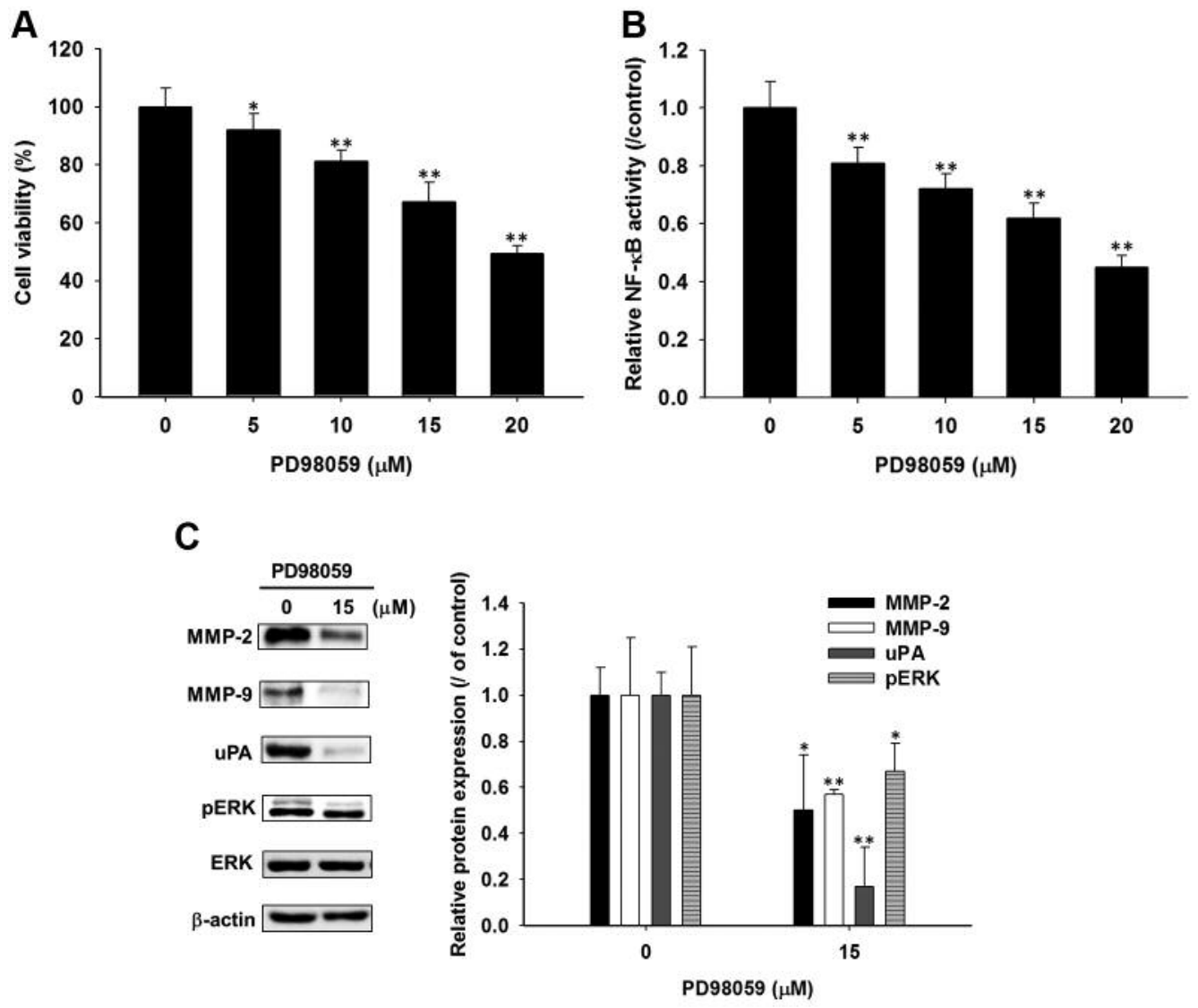

Figure 2. Effect of PD98059, ERK inhibitor on cell viability, $N F-k B$ activation, and metastasis related proteins and ERK phosphorylation in SKHep1 cells. Cells were treated with 0-20 $\mathrm{M}$ PD98059 for $48 \mathrm{~h}$. A) Change of cell viability was analyzed with the MTT assay. B) NF-kB reporter gene assay was used to verify NF- $k B$ activation. C) Protein expression of MMP-2, MMP-9, uPA, phosphor-ERK (pERK) was assayed by western blot assays. $* p<0.05$ and ${ }^{* *} p<0.01$ compared to control $(0.1 \%$ DMSO treatment $)$.

where applicable, $p<0.01$ is denoted. Graphs and analyses were completed with Sigma plot software (version 10.0).

\section{Results}

Magnolol induced cytotoxicity, apoptosis, and diminished expression of anti-apoptotic proteins in SK-Hepl cells. MTT assay, detection of cell-cycle distribution and caspase-3 activity, and western blotting were used to evaluate the effect of magnolol on cell viability and apoptosis in SK-Hep1 cells. In Figure 1A, the cytotoxicity of magnolol in SK-Hep1 cells was dose-dependently increased by $0-150 \mu \mathrm{M}$ magnolol treatment. Both sub- $\mathrm{G}_{1}$ population and caspase- 3 activity were significantly increased by $20-40 \%$ after magnolol treatment compared to control (vehicle treatment) (Figure 1B, C). Additionally, the protein levels of survivin and XIAP, which play critical roles in the anti-apoptotic mechanisms, were both significantly reduced by magnolol treatment (Figure 1D). It was shown that cytotoxicity and apoptosis activity were increased and expression of anti-apoptotic proteins was reduced by magnolol.

PD98059, ERK inhibitor reduced $N F-k B$ activation and expression of metastasis related proteins in SK-Hepl cells. In order to verify the role of ERK inactivation on anti-metastatic mechanisms in HCC, SK-Hep1 cells were treated with different concentrations (0-20 $\mu \mathrm{M})$ of PD98059 for $48 \mathrm{~h}$, and then NF- $\mathrm{KB}$ activation and expression of metastasis-related proteins were evaluated by NF-kB reporter gene assay and western blotting. As shown in Figure 2A, ERK inhibitor, PD98059 significantly induced dose-dependent cytotoxicity in SK-Hep1 cells. As shown by the NF-kB reporter gene assay, PD98059 markedly suppressed NF-kB activation by $20-50 \%$ as compared to control group (Figure 2B). Moreover, expression of metastatic related proteins, such as MMP-2, MMP-9 and uPA were all suppressed by PD98059 (Figure 2C). As expected, PD98059 also induced ERK dephosphorylation in SK-Hep1 cells. 


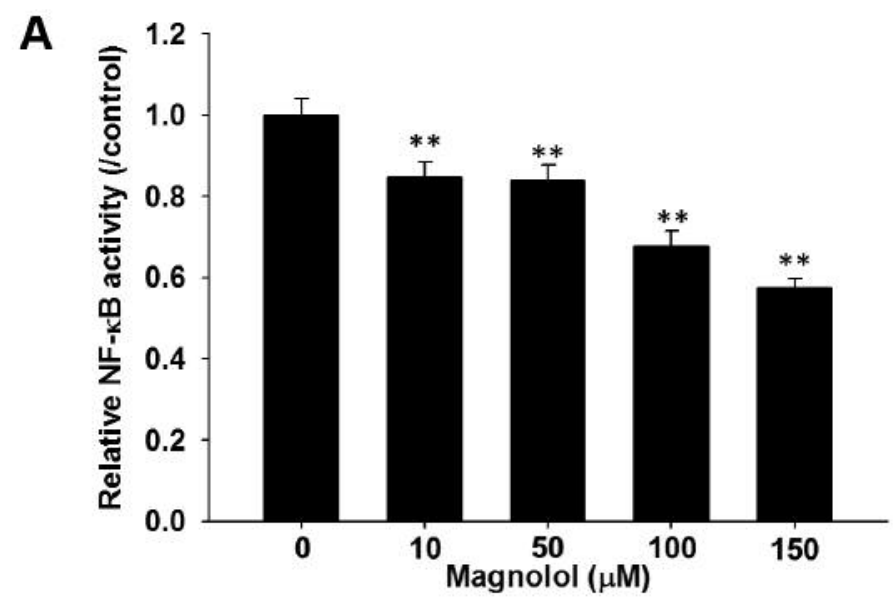

B
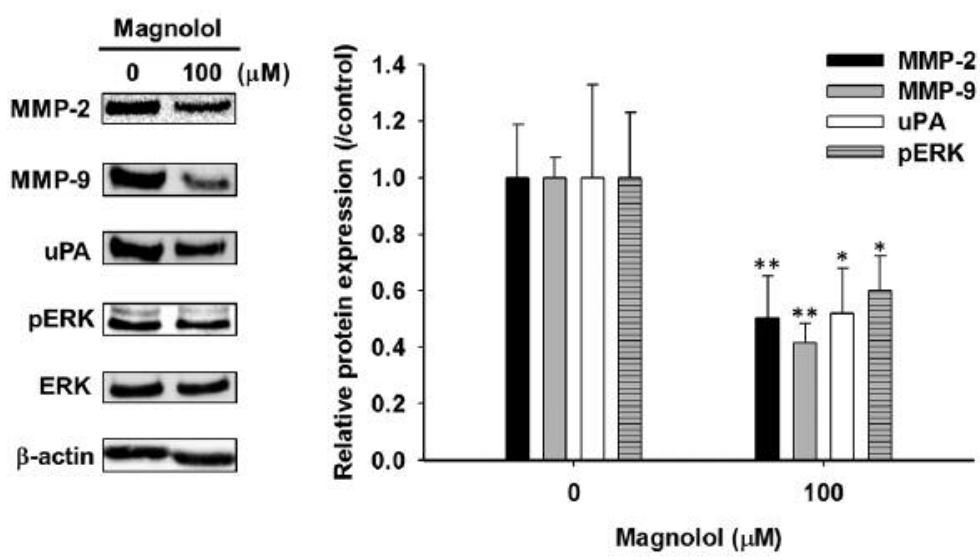

Figure 3. Effect of magnolol on NF-kB activation, metastasis-related proteins and ERK phosphorylation in SK-Hep1 cells. Cells were treated with 0-150 $\mu \mathrm{M}$ magnolol, respectively, for $48 \mathrm{~h}$. A) NF-kB activation was determined with $N F-k B$ reporter gene assay. B) Protein levels of MMP-2, MMP-9, uPA, phosphor-ERK ( $p$ ERK) were evaluated by western blot assays. $* p<0.05$ and $* * p<0.01$ compared to control ( $0.1 \%$ DMSO treatment).

Magnolol diminished $N F-K B$ activation and expression of metastasis related proteins via ERK dephosphorylation in SKHepl cells. Magnolol significantly decreased NF-kB activation by $16-43 \%$ compared to the control group (Figure $3 \mathrm{~A}$ ). Western blot was used to investigate the effect of magnolol on the expression of metastasis related proteins in SK-Hep1 cells. The protein levels of MMP2, MMP9 and UPA were significantly decreased by magnolol (Figure 3B). ERK phosphorylation was also reduced with magnolol by $40 \%$. In sum, magnolol could inhibit the ERK-mediated NF-KB activation and expression of metastasis related proteins in HCC.

Magnolol suppressed the invasion ability of SK-Hepl cells via blockage of ERK activation. To determine whether the invasion capacity of HCC was down-regulated by magnolol treatment, a transwell invasion assay was performed. In Figure
4A, the number of invading cells was noticeably decreased in the magnolol treated group. As displayed in Figure 4B, PD98059 also significantly suppresses the invasion capacity of SK-Hep1 cells. Here, magnolol diminished the invasion ability of HCC via blockage of ERK activation.

\section{Discussion}

Magnolol induces apoptosis through intracellular calcium accumulation, B-cell lymphoma 2 (BCL-2) down-regulation, and death receptor Fas-initiated extrinsic apoptotic pathway in HCC HepG2 cells (15). Both survivin and XIAP, member of the inhibitor of apoptosis protein (IAP) family, modulate anti-apoptotic response and contribute to anti-cancer drug resistance. XIAP directly binds to the active site of caspase3 leading to inhibition of caspase-3-induced DNA 


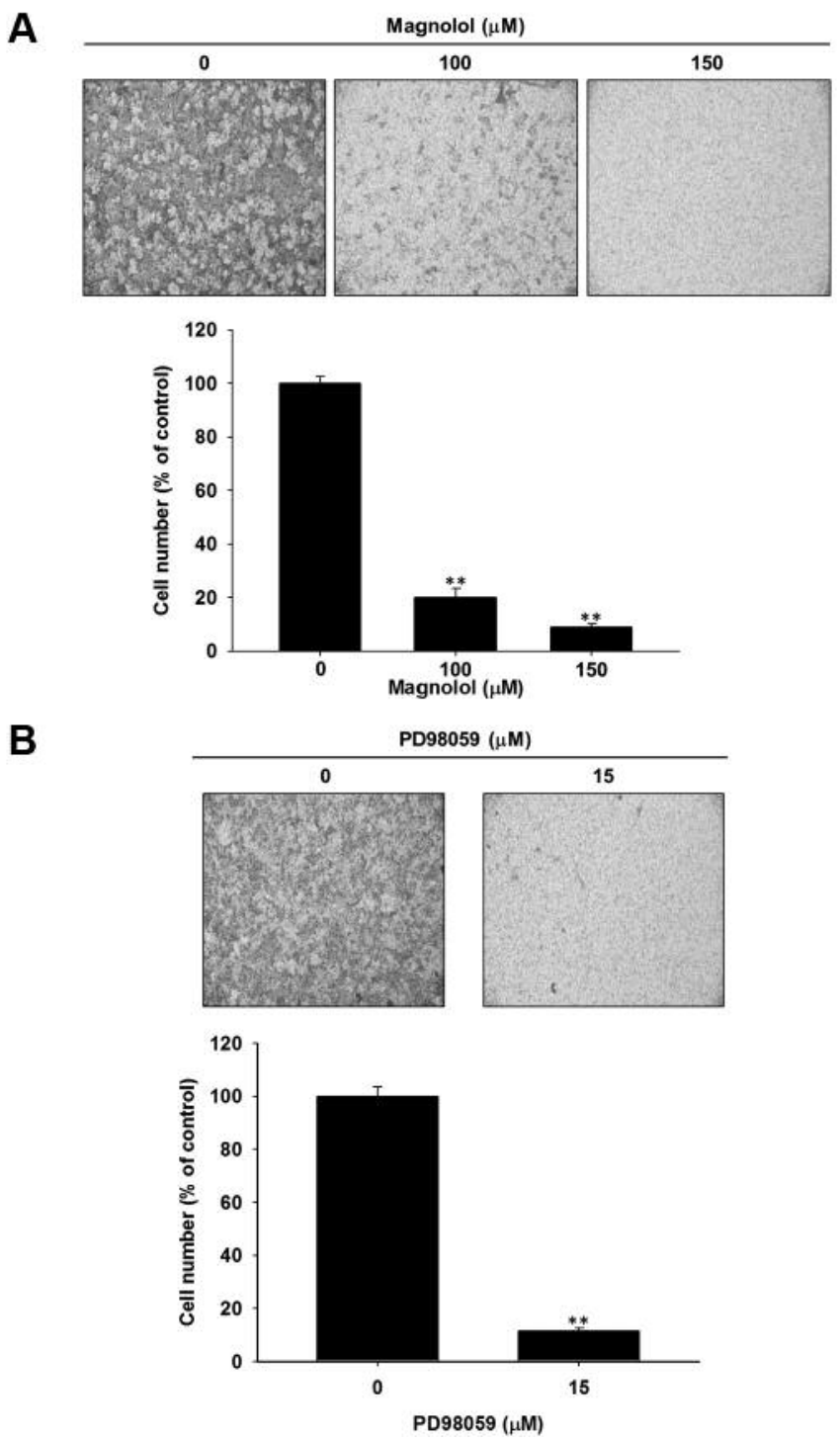

Figure 4. Effect of magnolol and PD98059 on invasion capacity of SK-Hep1. Cells were treated with different concentration magnolol or PD98059 for $48 \mathrm{~h}$, respectively. After treatments, invasion capacity of SK-Hepl was investigated with transwell invasion assay. A) Magnolol treatment, B) PD98059 treatment. ${ }^{*} p<0.05$ and ${ }^{* *} p<0.01$ compared to control $(0.1 \%$ DMSO treatment $)$.

fragmentation. Survivin plays a critical role in apoptosis inhibition and cell cycle progression (19-20). Overexpression of both XIAP and survivin correlates with poor prognosis in patients with HCC (21-22). As shown in Figure 1, magnolol significantly induced apoptosis and diminished protein levels of survivin and XIAP in SK-Hep1 cells. Magnolol not only induced apoptosis, but also inhibited the anti-apoptotic potential of HCC.

The overall survival of metastatic HCC patients is poor (23). Tumor metastasis is modulated by metastasis related proteins, such as matrix metalloproteinase-2 (MMP-2), matrix metalloproteinase-9 (MMP-9), and urokinase-type plasminogen activator (uPA). MMP-2 and MMP-9, $72 \mathrm{kDa}$ type IV collagenase and $92 \mathrm{kDa}$ type IV collagenase, elevate the invasive or metastatic ability of cancer cells through degradation of the basement membrane. uPA, a serine protease, activates conversion of plasminogen to protease plasmin which degrades extracellular matrix (ECM) and basement membrane (24). Overexpression of metastasis related proteins is associated with the invasiveness, metastasis, and prognosis of HCC (25-27). Magnolol inhibits cell invasion and protein levels of MMP-2 and MMP-9 in 
prostate cancer and cholangiocarcinoma (28-29). We also presented that magnolol decreased protein expression of MMP-2, MMP-9, and uPA and suppressed cell invasion in SK-Hep1 cells (Figure 3B and 4A).

NF-kB (p50/p65 transcription factor heterodimer) activation is essential for tumor metastasis because activated NF-kB up-regulates expression of metastasis related proteins encoded by NF-kB target genes (30). Extracellular signalregulated kinase (ERK), mitogen-activated protein kinase, regulates NF-kB-modulated metastasis potential in $\mathrm{HCC}$. Previous studies showed that ERK dephosphorylation inhibited NF-kB-modulated cell invasion and expression of metastasis-related proteins in HCC SK-Hep1 and Huh7 cells $(5,31)$. Liu et al., found that magnolol suppressed NF-KBmodulated breast cancer cell invasion, but had no effect on ERK activation (32). Some studies presented magnolol to mediate cell cycle arrest through inducing ERK phosphorylation in bladder and colon cancer cells (33-34). High expression of pERK is linked to poor prognosis and may serve as a potential therapeutic target in HCC (35-36). In addition to inhibition of NF-kB-modulated metastatic potential, magnolol also induced ERK dephosphorylation in HCC SK-Hep1 cells (Figures 3A, B, 4A). In conclusion, this study demonstrated that magnolol could be a therapeutic adjuvant treatment, that induced apoptosis and inhibited ERK-modulated metastatic potential in HCC.

\section{Conflicts of Interest}

The Authors declare no competing financial interests regarding this study.

\section{Acknowledgements}

The present study was supported by the Taipei Cathay General Hospital (grant no. CGH-MR- A10330, CGH-MR- A106019, CGHMR-A10407), the Yilan National Yang-Ming University Hospital (grant no. RD2018-019) The Authors acknowledge the technical services provided by Clinical Medicine Research Laboratory of National Yang-Ming University Hospital and Translational Laboratory.

\section{References}

1 Balogh J, Victor D, Asham EH, Burroughs SG, Boktour M, Saharia A, Li X, Ghobrial RM and Monsour HP Jr.: Hepatocellular carcinoma: a review. J Hepatocell Carcinoma 3: 41-53, 2016

2 Chiang IT, Chen WT, Tseng CW, Chen YC, Kuo YC, Chen BJ, Weng MC, Lin HJ and Wang WS: Hyperforin inhibits cell growth by inducing intrinsic and extrinsic apoptotic pathways in hepatocellular carcinoma cells. Anticancer Res 37: 161-167, 2017.

3 Chiang IT, Liu YC, Wang WH, Hsu FT, Chen HW, Lin WJ, Chang WY and Hwang JJ: Sorafenib inhibits TPA-induced MMP-9 and VEGF expression via suppression of ERK/NF-kappaB pathway in hepatocellular carcinoma cells. In Vivo 26: 671-681, 2012.
4 Wang Z, Zhang G, Wu J and Jia M: Adjuvant therapy for hepatocellular carcinoma: current situation and prospect. Drug Discov Ther 7: 137-143, 2013.

5 Hsu FT, Liu YC, Chiang IT, Liu RS, Wang HE, Lin WJ and Hwang JJ: Sorafenib increases efficacy of vorinostat against human hepatocellular carcinoma through transduction inhibition of vorinostat-induced ERK/NF-kappaB signaling. Int J Oncol 45: 177-188, 2014.

6 Weng MC, Wang MH, Tsai JJ, Kuo YC, Liu YC, Hsu FT and Wang HE: Regorafenib inhibits tumor progression through suppression of ERK/NF-kappaB activation in hepatocellular carcinoma bearing mice. Biosci Rep 38, 2018. doi: 10.1042/BSR20171264

$7 \mathrm{Hu} \mathrm{Y,} \mathrm{Wang} \mathrm{S,} \mathrm{Wu} \mathrm{X,} \mathrm{Zhang} \mathrm{J,} \mathrm{Chen} \mathrm{R,} \mathrm{Chen} \mathrm{M} \mathrm{and} \mathrm{Wang} \mathrm{Y:}$ Chinese herbal medicine-derived compounds for cancer therapy: a focus on hepatocellular carcinoma. J Ethnopharmacol 149: 601-612, 2013.

8 Wang WH, Chiang IT, Ding K, Chung JG, Lin WJ, Lin SS and Hwang JJ: Curcumin-induced apoptosis in human hepatocellular carcinoma j5 cells: critical role of ca(+2)-dependent pathway. Evid Based Complement Alternat Med 2012: 512907, 2012.

9 Liao CY, Lee CC, Tsai CC, Hsueh CW, Wang CC, Chen IH, Tsai MK, Liu MY, Hsieh AT, Su KJ, Wu HM, Huang SC, Wang YC, Wang CY, Huang SF, Yeh YC, Ben RJ, Chien ST, Hsu CW and Kuo WH: Novel investigations of flavonoids as chemopreventive agents for hepatocellular carcinoma. Biomed Res Int 2015: 840542, 2015.

10 Yang Z, Liao X, Lu Y, Xu Q, Tang B, Chen X and Yu Y: Addon therapy with traditional chinese medicine improves outcomes and reduces adverse events in hepatocellular carcinoma: A metaanalysis of randomized controlled trials. Evid Based Complement Alternat Med 2017: 3428253, 2017.

11 Lin JJ, Jin CN, Zheng ML, Ouyang XN, Zeng JX and Dai XH: Clinical study on treatment of primary hepatocellular carcinoma by Shenqi mixture combined with microwave coagulation. Chin J Integr Med 11: 104-110, 2005.

12 Poivre $M$ and Duez P: Biological activity and toxicity of the Chinese herb Magnolia officinalis Rehder \& E. Wilson (Houpo) and its constituents. J Zhejiang Univ Sci B 18: 194-214, 2017.

13 Chen JH, Kuo HC, Lee KF and Tsai TH: Magnolol protects neurons against ischemia injury via the down-regulation of p38/MAPK, CHOP and nitrotyrosine. Toxicol Appl Pharmacol 279: 294-302, 2014.

$14 \mathrm{Xu}$ HL, Tang W, Du GH and Kokudo N: Targeting apoptosis pathways in cancer with magnolol and honokiol, bioactive constituents of the bark of Magnolia officinalis. Drug Discov Ther 5: 202-210, 2011.

15 Lin SY, Chang YT, Liu JD, Yu CH, Ho YS, Lee YH and Lee WS: Molecular mechanisms of apoptosis induced by magnolol in colon and liver cancer cells. Mol Carcinog 2: 73-83, 2001.

16 Tsai JJ, Pan PJ and Hsu FT: Regorafenib induces extrinsic and intrinsic apoptosis through inhibition of ERK/NF-kappaB activation in hepatocellular carcinoma cells. Oncol Rep 37: 1036-1044, 2017.

17 Hsu FT, Liu HS, Ali AAA, Tsai PH, Kao YC, Lu CF, Huang HS and Chen CY: Assessing the selective therapeutic efficacy of superparamagnetic erlotinib nanoparticles in lung cancer by using quantitative magnetic resonance imaging and a nuclear factor kappa-B reporter gene system. Nanomedicine 14: 1019$31,2018$. 
18 Lai KC, Hsu SC, Kuo CL, Ip SW, Yang JS, Hsu YM Huang HY, Wu SH and Chung JG: Phenethyl isothiocyanate inhibited tumor migration and invasion via suppressing multiple signal transduction pathways in human colon cancer HT29 cells. J Agric Food Chem 58: 11148-11155, 2010.

19 Augello C, Caruso L, Maggioni M, Donadon M, Montorsi M, Santambrogio R, Torzilli G, Vaira V, Pellegrini C, Roncalli M, Coggi $\mathrm{G}$ and Bosari S: Inhibitors of apoptosis proteins (IAPs) expression and their prognostic significance in hepatocellular carcinoma. BMC Cancer 9: 125, 2009.

20 Wolf BB, Schuler M, Echeverri F and Green DR: Caspase-3 is the primary activator of apoptotic DNA fragmentation via DNA fragmentation factor-45/inhibitor of caspase-activated DNase inactivation. J Biol Chem 274: 30651-30656, 1999.

21 Che Y, Ye F, Xu R, Qing H, Wang X, Yin F, Cui M, Burstein D, Jiang B and Zhang DY: Co-expression of XIAP and cyclin D1 complex correlates with poor prognosis in patients with hepatocellular carcinoma. Am J Pathol 180: 1798-1807, 2012.

22 Ye CP, Qiu CZ, Huang ZX, Su QC, Zhuang W, Wu RL and Li XF: Relationship between survivin expression and recurrence, and prognosis in hepatocellular carcinoma. World J Gastroenterol 13: 6264-6268, 2007.

23 Kummar S and Shafi NQ: Metastatic hepatocellular carcinoma. Clin Oncol (R Coll Radiol) 15: 288-294, 2003.

24 Pan PJ, Tsai JJ and Liu YC: Amentoflavone inhibits metastatic potential through suppression of ERK/NF- $\mathrm{kB}$ activation in osteosarcoma U2OS cells. Anticancer Res 37: 4911-4918, 2017.

25 Wang B, Ding YM, Fan P, Wang B, Xu JH and Wang WX: Expression and significance of MMP2 and HIF-1 $\alpha$ in hepatocellular carcinoma. Oncol Lett 8: 539-546, 2014.

26 Nart D, Yaman B, Yilmaz F, Zeytunlu M, Karasu Z and Kiliç M: Expression of matrix metalloproteinase-9 in predicting prognosis of hepatocellular carcinoma after liver transplantation. Liver Transpl 16: 621-630, 2010.

27 Zheng Q, Tang ZY, Xue Q, Shi DR, Song HY and Tang HB: Invasion and metastasis of hepatocellular carcinoma in relation to urokinase-type plasminogen activator, its receptor and inhibitor. J Cancer Res Clin Oncol 126: 641-646, 2000.

28 Hwang ES and Park KK: Magnolol suppresses metastasis via inhibition of invasion, migration, and matrixmetalloproteinase2/-9 activities in PC-3 human prostate carcinoma cells. Biosci Biotechnol Biochem 74: 961-967, 2010.
29 Zhang FH, Ren HY, Shen JX, Zhang XY, Ye HM and Shen DY: Magnolol suppresses the proliferation and invasion of cholangiocarcinoma cells via inhibiting the NF-kB signaling pathway. Biomed Pharmacother 94: 474-480, 2017.

30 Liu YC, Wu RH and Wang WS: Regorafenib diminishes the expression and secretion of angiogenesis and metastasis associated proteins and inhibits cell invasion via NF-KB inactivation in SK-Hep1 cells. Oncol Lett 14: 461-467, 2017.

31 Lee KC, Tsai JJ, Tseng CW, Kuo YC, Chuang YC, Lin SS and Hsu FT: Amentoflavone inhibits ERK-modulated tumor progression in hepatocellular carcinoma in vitro. In Vivo 32: 549-554, 2018.

32 Liu Y, Cao W, Zhang B, Liu YQ, Wang ZY, Wu YP, Yu XJ, Zhang XD, Ming PH, Zhou GB and Huang L: The natural compound magnolol inhibits invasion and exhibits potential in human breast cancertherapy. Sci Rep 3: 3098, 2013.

33 Lee SJ, Cho YH, Park K, Kim EJ, Jung KH, Park SS, Kim WJ and Moon SK: Magnolol elicits activation of the extracellular signal-regulated kinase pathway by inducing p27KIP1-mediated G2/M-phase cell cycle arrest in human urinary bladder cancer 5637 cells. Biochem Pharmacol 75: 2289-2300, 2008.

34 Hsu YF, Lee TS, Lin SY, Hsu SP, Juan SH, Hsu YH, Zhong WB and Lee WS: Involvement of Ras/Raf-1/ERK actions in the magnolol-induced upregulation of p21 and cell-cycle arrest in colon cancer cells. Mol Carcinog 46: 275-283, 2007.

35 Schmitz KJ, Wohlschlaeger J, Lang H, Sotiropoulos GC, Malago M, Steveling K, Reis H, Cicinnati VR, Schmid KW and Baba HA: Activation of the ERK and AKT signalling pathway predicts poor prognosis in hepatocellular carcinoma and ERK activation in cancer tissue is associated with hepatitis $\mathrm{C}$ virus infection. J Hepatol 48: 83-90, 2008.

36 Liang Y, Chen J, Yu Q, Ji T, Zhang B, Xu J, Dai Y, Xie Y, Lin $\mathrm{H}$, Liang $\mathrm{X}$ and Cai $\mathrm{X}$ : Phosphorylated ERK is potential prognostic biomarker for sorafenib response in hepatocellular carcinoma. Cancer Med 6: 2787-2795, 2017. 